\title{
A detailed analysis of how an urban trail system affects cyclists' travel
}

\author{
Kevin J. Krizek · Ahmed El-Geneidy · Kristin Thompson
}

Published online: 18 July 2007

(C) Springer Science+Business Media B.V. 2007

\begin{abstract}
Transportation specialists, urban planners, and public health officials have been steadfast in encouraging active modes of transportation over the past decades. Conventional thinking, however, suggests that providing infrastructure for cycling and walking in the form of off-street trails is critically important. An outstanding question in the literature is how one's travel is affected by the use of such facilities and specifically, the role of distance to the trail in using such facilities. This research describes a highly detailed analysis of use along an off-street facility in Minneapolis, Minnesota, USA. The core questions addressed in this investigation aim to understand relationships between: (1) the propensity of using the trail based on distance from the trip origin and destination, and (2) how far out of their way trail users travel for the benefit of using the trail and explanatory factors for doing so. The data used in the analysis for this research was collected as a human intercept survey along a section of an off-street facility. The analysis demonstrates that a cogent distance decay pattern exists and that the decay function varies by trip purpose. Furthermore, we find that bicyclists travel, on average, 67\% longer in order to include the trail facility on their route. The paper concludes by explaining how the distance decay and shortest path versus taken path analysis can aid in the planning and analysis of new trail systems.
\end{abstract}

Keywords Non-motorized transportation · Cycling · Infrastructure · Distance decay $\cdot$ Route choice $\cdot$ Sustainability

K. J. Krizek $(\square)$

Active Communities/Transportation (ACT) Research Group, University of Colorado, Environmental Design Building, Campus Box 314, Boulder, CO 80309-0314, USA

e-mail: kjkrizek@gmail.com

K. J. Krizek

Planning and Design, University of Colorado, Boulder, CO, USA

A. El-Geneidy · K. Thompson

Active Communities/Transportation (ACT) Research Group, Humphrey Institute of Public Affairs, University of Minnesota, 301 19th Ave S., Minneapolis, MN 55455, USA

e-mail: geneidy@umn.edu 


\section{Introduction}

Transportation specialists, urban planners, and public health officials have been steadfast in encouraging active modes of transportation over the past decades. While the motives for doing so may differ somewhat between professions-urban planners to enhance quality of life, transportation specialists to mitigate congestion, public health to increase physical activity - each ardently aim to increase levels of walking and cycling. Decisions to walk or bicycle are the outcome of myriad factors. Conventional thinking, however, suggests that providing infrastructure for cycling and walking in the form of off-street trails is critically important. An outstanding question in the literature is how one's travel is affected by the use of such facilities.

This research describes a highly detailed analysis of use along an off-street facility in Minneapolis, Minnesota, USA. In contrast to other studies which tend to be restricted to examining type, time, and intensity of use of non-motorized facilities, our investigation complements such data with overall travel activity, origin and destination locations, and select route choice data to better position this emerging body of literature against the larger picture of one's travel patterns. The core questions addressed in this investigation aim to understand relationships between: (1) the propensity of using the trail based on distance from the trip origin and destination, and (2) how far out of their way trail users travel for the benefit of using the trail and some explanatory factors for doing so.

The analysis portion of the paper is divided along the lines of each of the questions previously mentioned. We first review available literature on these issues. The data source used in the analysis for this research was collected as a human intercept survey along a part of an off-street facility. The central focus of this investigation turns to describing a variety of distance-decay functions and analysis to determine additional distance traveled by cyclists when using trails and the factors leading to such additional distance.

\section{Relevant literature}

Literature examining relationships between the built environment and non-motorized travel, particularly cycling, is burgeoning. Past theoretical work offers conceptual frameworks to understand specific relationships between specialized facilities and cycling (Pikora et al. 2003). Subsequently, empirical research has sought to shed light on relatively general claims suggesting that facilities help induce use-a claim that has been analyzed at various levels of geography. For example, using seven case studies of North American cities, researchers have examined several different factors affecting levels of cycling (Pucher et al. 1999), concluding that infrastructure is one of several factors affecting cycling. Other city-wide comparisons also suggest the strong role of culture (Rietveld and Daniel 2004). Focusing on 35 cities across the U.S., other work examined correlations between facilities and levels of bicycle commuting (Nelson and Allen 1997; Dill and Carr 2003). The more recent and updated version of this analysis found the strongest correlation to be between bicycle commute mode share and the number of off-street bike lanes per square mile.

Studies that employ relatively large units of analysis (e.g., an entire community or even census tracts), however, are considerably limited in their ability to address relationships 
between specific facilities and patterns of use. Therefore, other research focuses on more specific units of analysis (e.g., specific trails). For example, some studies examine patterns of use along specific trails noting counts (Hunter and Huang 1995), times of use (Lindsey et al. 2004), purpose of travel (Merom et al. 2003) or relationship to levels of physical activity (Troped et al., 2001). Still, studies of this variety fail to fully capture the dimension of who is using the facility and their geographical distribution, most notably where they traveled from. Such information is helpful because the distance traveled to use a bicycle facility could be used as a measure of the desire to use-or in economists' terms, a willingness to pay-for cycling infrastructure investments.

Some available research hones in on elements of this question looking at the additional distance users are willing to travel for facilities. For example, Shafizadeh and Niemeier (1997) used intercept surveys along a well-known bicycle trail in Seattle to investigate the role of proximity to an off-road bicycle trail in affecting route choice decisions. They found that as the distance between the trip origin and the off-road trail increases, travel time increases to a point and then decreases. This led them to conclude that a 0.5 to 0.75 mile "bike shed" could exist around an off-road bike path, within which individuals will be willing to increase their travel time to access that facility and outside of which individuals preferred a more direct route. In a different revealed preference investigation, Aultmann-Hall et al. (1997) used GIS to investigate bicycle commuter routes in Guelph, Canada. They compared participants' shortest paths to their actual paths, learning that people diverge little from the shortest path, and that most bicycle commuters use major road routes. Stinson and Bhat (2003) administered an Internet-based stated preference survey and used the data to estimate a logit model of how facility attributes affected commuter route choice. While their model showed that the most important variable affecting route preference was travel time, the facility type had a statistically significant effect on route choice. In particular, they found that cyclists are willing to tolerate about $10 \%$ longer travel times in order to use routes on residential streets and routes with a bicycle facility at bridge locations rather than routes on minor and major arterials with no bicycle facility at bridge locations. Finally, using a computer-based adaptive stated preference survey, Tilahun et al. (2005) surveyed 167 people to learn that cyclists are willing to travel up to $20 \mathrm{~min}$ more (assuming a baseline 20 min commute) to switch from an unmarked on-road facility with side parking to an off-road bicycle trail, with smaller changes associated with less dramatic improvements.

Even considering the above findings, two different phenomena remain outstanding. The first relates to the distance users are willing to travel to use a trail or a facility. For example, the pedestrian literature widely cites that people are willing to walk a quarter mile or so- a finding most reliably traced back to writings offered in the early 1980's (Untermann 1984). The cycling literature is absent of such a threshold (based on either empirics or assertions), probably because such a threshold would inevitably depend on the characteristics and overall quality of the facility. The second has to do with understanding the myriad factors associated with the route or trip purpose (e.g., intersections) involved in traveling a further distance, especially for a highly desirable trail facility.

Furthermore, existing studies have limited applicability because the research may be based on: hypothetical scenarios (e.g., stated preference); a lack of a consistent type of facilities connecting common origins and destinations; an inability to provide realistic scenarios for comparison; and/or potentially biased samples of respondents (e.g., the sampled bicyclists were tolerant of environments too risky to be acceptable to the larger 
population). This paper tackles such shortcomings in the available research by examining the travel behavior of cyclists along a highly desirable urban trail. We respond to two separate but related questions: (a) addressing distance-decay curves, showing how far users traveled to use the facility, and (b) explaining how far out of their way cyclists are willing to travel to use the facility.

\section{Description of survey and data}

The analysis employs data collected from users of an urban trail system that spans southern Minneapolis, Minnesota, and an adjoining suburb to the west (St. Louis Park). The Twin Cities metropolitan region boasts a trail system unparalleled among major metropolitan areas in the U.S., totaling over 2,722 kilometers (1,692 miles). While not nearly as extensive, striped on-street bike lanes are common as well. The network of on- and offstreet trails is accessible to most residents, with $90 \%$ of homes within $1,600 \mathrm{~m}$ (one mile) of an off-street trail. Furthermore, Twin Cities residents cherish their bicycle trails, especially in the summer months. Ten percent of Minnesota adults bike to work or school at least once a year (Pucher and Renne 2003). In 2000, Minneapolis was the number three bike commuting city nationwide (after Tucson and San Francisco, but ahead of more popular bicycling oriented cities such as Seattle, WA and Portland, OR), with 1.9-2.6\% of commuters biking to work (Dill and Carr 2003).

The specific data used in this analysis was collected in the summer of 2005 as an intercept survey at 13 locations along part of a well-established and highly desirable urban trail system (for photographs of the trail, see Fig. 1a, b). The 13 data collection sites were distributed over three parts of the trail: the Kenilworth section (the north spur), the Midtown Greenway (the east spur), and the Southwest trail (the southwest spur) (see Fig. 2).

Hennepin County administered the survey and collected data in 5-h shifts at varying times of day and days of the week. In most cases, the same location was surveyed twice. All trail users were prompted to fill out a four-page survey which was completed by an estimated one-half of all users. The survey included questions about respondents' activities on the trail, frequency of trail use, residential location, general activity level, and satisfaction with the trail system. Also included were an half dozen questions focusing on their current trip (hereafter referred to as the reference trip), specifying information about their trip origin, destination, purpose, etc. Responses from the reference trip are used as the basis for this analysis.

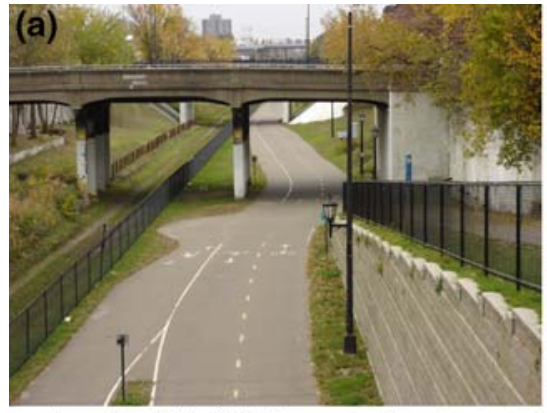

Location \#3 of Midtown section

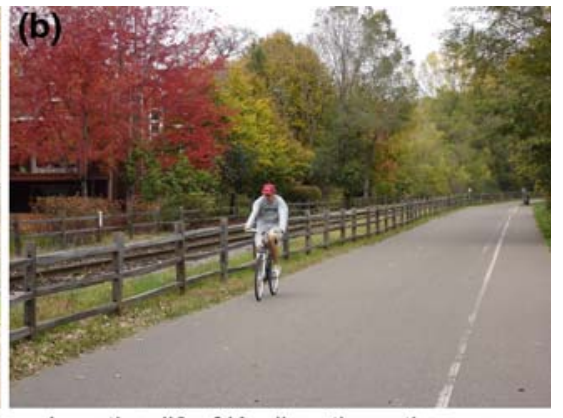

Location \#3 of Kenilworth section

Fig. 1 Photographs of trail sections (source: Kevin J. Krizek) 


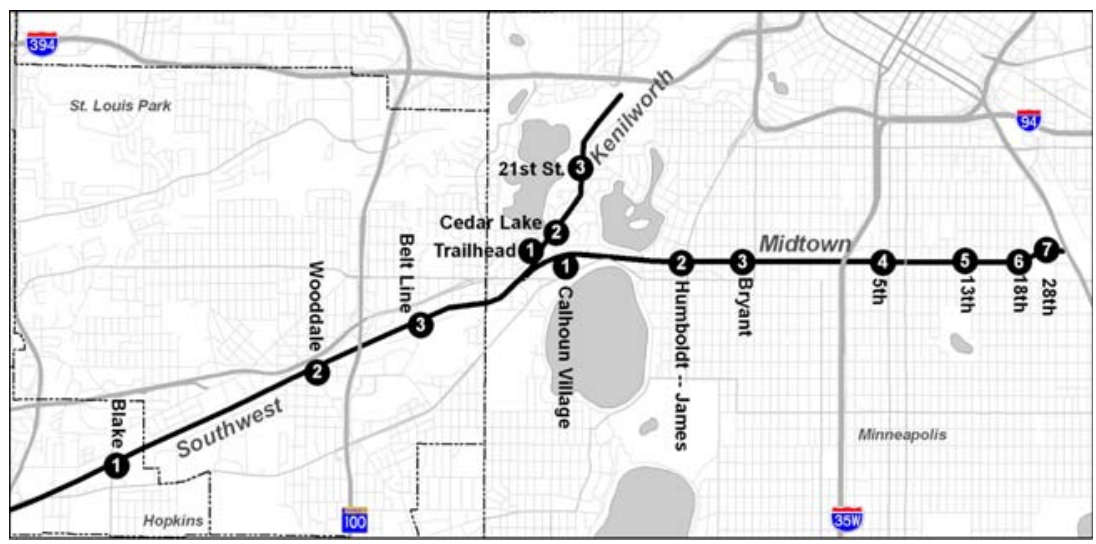

Fig. 2 Locations where survey was administered

\section{Distance-decay function}

Distance-decay functions are a relatively straightforward, yet robust, way to understand the spatial behavior of travelers and can be used for any mode of transportation planning. Decay functions specify the distribution of trip lengths as a function of a measure of impedance to travel (typically measured in the form of time or distance) (Taylor 1975; Luoma et al. 1993). Specifically, decay functions are estimated in one of two ways. The first requires a general survey of the population and would measure the percentage of neighborhood residents (e.g., by census tract/block group) that use the trail and determine how the percentage varies with distance from the access points. This approach would survey both users and non-users of the activity, in this case use of trail. The second approach, and the strategy used herein, focuses on users of the activity to learn how far they are willing to travel, a concept often applied to transit (Zhao et al. 2003).

As the name implies, distance has a decaying effect on the likelihood of travel between two locations. The function is a general measure, incorporating vast amounts of information about the structure of transportation networks, as well as surrounding land uses and urban form. One might expect the shape of the function to vary by the purpose of the trips. For example, shopping trips via bicycle would have more residents cycling shorter distances for a trail (assuming users are burdened with the need to carry purchases); recreational trips might exhibit a flatter curve, as one is free of the need to carry goods free of time constraints. Either way, intuition suggests that trail users are more likely to have trip origins closer to the trail than further away.

We mapped the home location of each respondent and noted the trail entrance and exit location as well as the self-reported purpose of the reference trip. ${ }^{1,2}$ Of the total 3,121

\footnotetext{
1 The survey allowed eight reasons for using the trail. In the interest of parsimony, we aggregated the responses into three categories: work/school (commute to work; go to or from school/university), shopping (go shopping/run errands), recreation (get exercise, walk pet, enjoy scenery, socialize, go to meet family/ friends).

2 In a perfect world, we would also be able to use their described origin and destination location. For reasons described in a later footnote, this field was not well populated with usable information. In order to maximize the number of respondents used to estimate the distance-decay curves, we assumed respondents were traveling to or from their home and calculated the network distance from their home location to the nearest trail access point (entrance or exit) — an assumption we feel preserves the integrity of the data.
} 


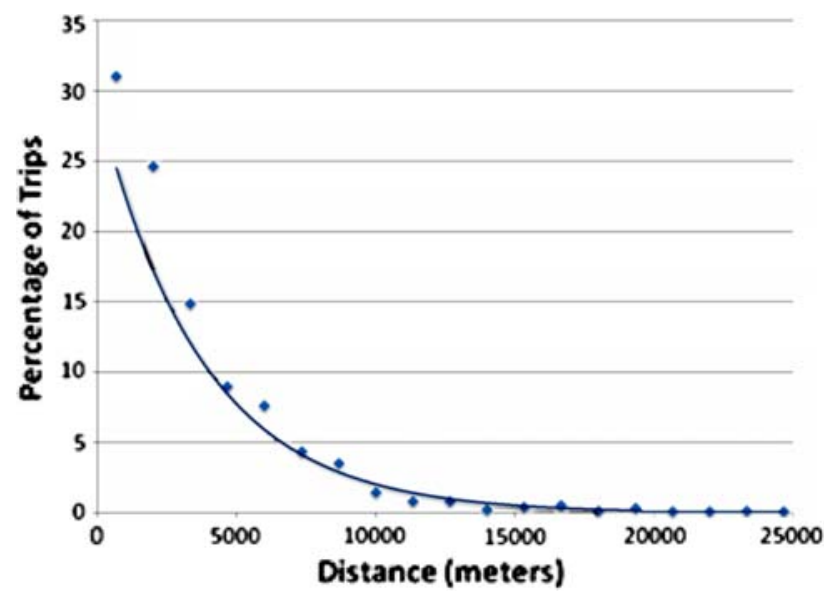

Fig. 3 Distance decay for trail users (for cyclists)

respondents with usable responses for the above questions, $75 \%$ of them reported cycling to the trail, $12 \%$ used auto, and $8.5 \%$ walked. $^{3}$ The overwhelming majority of respondents cycled to the trail and along the trail; we therefore estimate distance-decay curves for these users.

The manner in which distance to the trail (the $x$-axis) is measured is also an important matter in this exercise, especially considering shorter travel distances of cycling. Two predominant strategies are Euclidian and network; the former measures the simple straight line distance between two points (a.k.a. the distance as the crow flies). The latter measures the distance required to travel on a network (typically road) between two points. An added consideration in this research is the fact that the trail has limited access points. ${ }^{4}$

Figure 3 depicts the distance-decay curve for all respondents, showing the percentage of users cycling from various distances away from the trail. Over one-half of the users cycle less than 2,500 $\mathrm{m}$ to use the trail and more than three-quarters of the users cycle less than $5,000 \mathrm{~m}$; the curve quickly flattens out after this distance as the remaining one-quarter of the users travel distances ranging from 5,000 to 25,000 $\mathrm{m}$ from the nearest access point. The fitted exponential curve has an $R^{2}$ of 0.938 , and a functional form of $29.29^{*} \mathrm{exp}$ $(-00.001 x)$, where $x$ is the network distance from origin or destination to the point of entrance or exit of the trail respectively.

Figure 4 displays distance-decay curves by three different purposes of the reference trip. The difference in the distance effects among the three trip purposes is confirmed by visually inspecting the different distance-decay curves; also, note differences in associated parameters presented in Table 1. Respondents using the trail for shopping and work display the steepest decay curve (respondents are less willing to use the facility for this type of trip), with shopping having a slight steeper form. As expected, those using the trail for recreational purpose display the flattest curve that also extends for longer distances.

\footnotetext{
3 While the trail system is very attractive, Fig. 2 shows over half of the survey locations are within 10 or so blocks of the "Chain of Lakes" in Minneapolis. This area is highly cherished among walkers due to its recreational and scenic amenities, which helps explain the relatively low levels of walking along the nearby trail being analyzed.

4 The trail was not accessible at every street intersection because of grade separation. This analysis only measures network distances to each access point in the trail.
} 


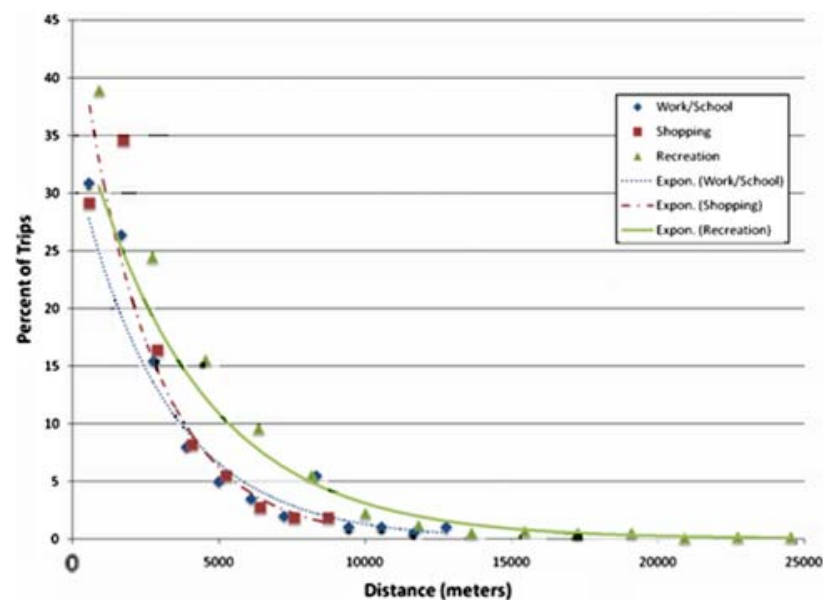

Fig. 4 Distance decay by trip purpose (for cyclists)

Table 1 Distance decay functions

\begin{tabular}{lrlll}
\hline Trip purpose & \multicolumn{1}{l}{$N$} & Coefficient & Exp & $R^{2}$ \\
\hline Recreation & 1,172 & 38.55 & $-0.001 x$ & 0.94 \\
Work/school & 201 & 33.28 & $-0.001 x$ & 0.898 \\
Shopping/errands & 112 & 47.64 & $-0.0001 x$ & 0.957 \\
Total sample & 1,486 & 29.29 & $-0.001 x$ & 0.938 \\
\hline
\end{tabular}

\section{Shortest distance versus distance traveled}

Given the limited data requirements, the distance-decay functions provide robust measures of how far cyclists are willing to travel to use a trail. An alternative method to understand the so-called "value" of the trail to users is to learn how far out of their way they are willing to travel to use the facility. We now turn to examining route choice decisions by comparing a cyclist's chosen path using the trail relative to the shortest distance between their stated origin and destination (see Fig. 5, for example).

Key data for this exercise included characteristics of the reference trip presented above (access location, purpose, and mode); however, mapping route information also requires data about the specific origin of the trip, ${ }^{5}$ the exit location, and final destination. ${ }^{6}$ To determine the distance of the path taken by respondents, we calculated three distance segments: (1) the shortest path distance from origin to trail access point, (2) the distance

\footnotetext{
5 For this latter analysis, we used responses from the specific origin, rather than their home location. The poor reporting of the data, however, considerably lowered the number of usable responses (described further below).

${ }^{6}$ Satisfying all of these requirements considerably lowered the number of usable responses. For example, a total of 595 respondents answered each of these questions. Another 420 respondents were eliminated for providing unidentifiable locations (i.e., "drugstore") or for listing the same access and egress point (e.g., a recreational "loop" trip). Finally, non-cyclists and respondents that did not specify a trip purpose or had a missing value in any field were excluded. The remaining 142 records were included in the statistical analysis.
} 


\section{Origin Destination Analysis: Traveled Path vs. Shortest Path}

Trial Data Point 1
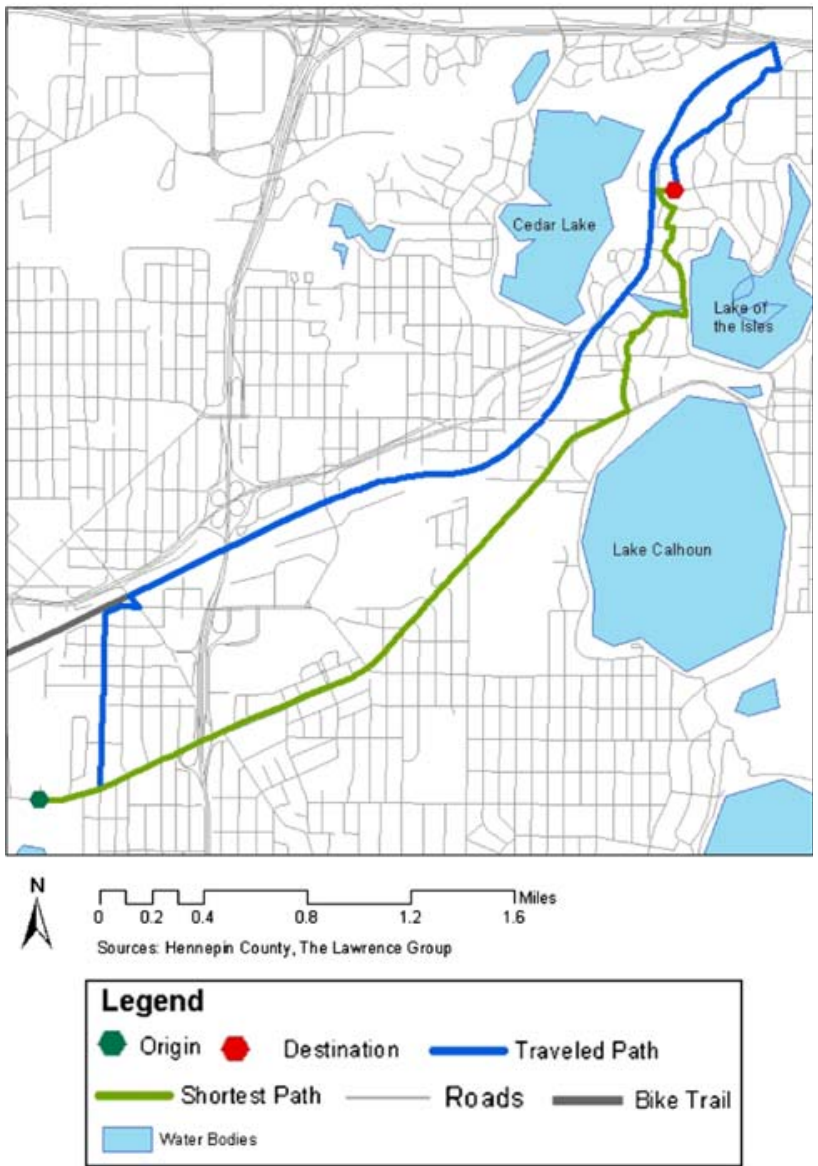

Fig. 5 Visual depiction of shortest distance versus distance traveled

traveled on the trail from access to egress point, and (3) the shortest path distance from the egress point to the destination. The shortest path distance was skimmed using the same network file consisting of roads and trails available to bicyclists; the route may or may not have included bicycle specific facilities.

\section{Analysis}

A difference variable was calculated by subtracting the distance of the calculated shortest route from the distance of the route taken. The median of these differences is $1,082 \mathrm{~m}$ ( 0.67 miles) and the mean is $2,761 \mathrm{~m}$ (1.715 miles), with a standard deviation of 4,050 . Figure 6 displays the large right tail of the distribution; the difference for over half of the respondents was between 0 and 1,200 $\mathrm{m}$ ( 0 and 0.74 miles). 


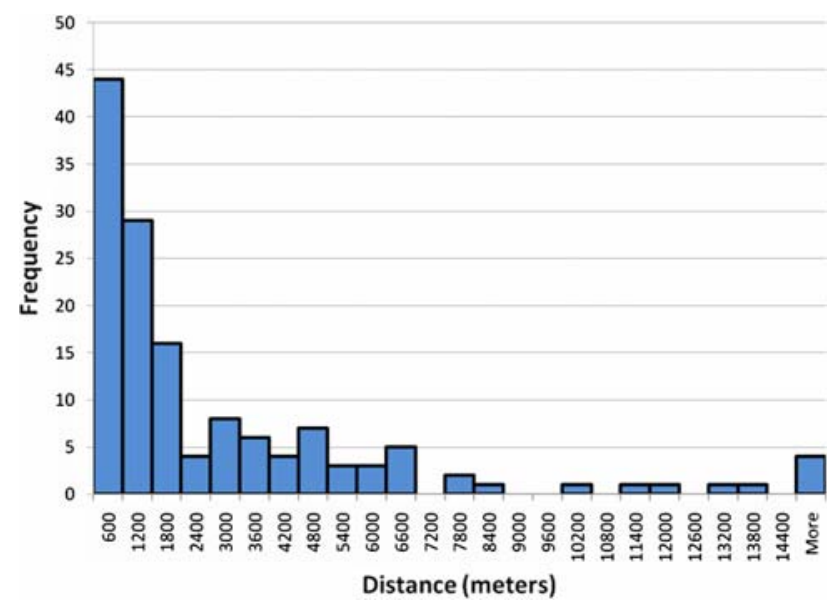

Fig. 6 Frequency distribution: distance traveled minus shortest distance

We first used a paired samples $T$-test to compare the difference in the means of the shortest route distance with the mean taken route distance, a result that was statistically significant at the $99 \%$ level of confidence $(t=-8.09)$. Given that the routes selected by trail users were longer than shortest path distances, our next aim was to employ two ordinary least squares (OLS) regression models to more robustly explain this finding. The first model estimates, in a multivariate context, the additional distance residents are willing to travel than the shortest distance. The second model aims to explain factors leading to differences between the chosen and the shortest route.

The independent variables used in each model have been gleaned from, or relate to, characteristics other studies have found to be important when focusing on cyclist travel behavior; the variables can be grouped roughly into two categories: characteristics of the respondent and characteristics of the trip. Characteristics of the respondent include demographic variables such as age, race, and gender, and the person's activity level and city of residence. Characteristics of the trip include trip purpose, trip mode, time of day, and the distance traveled on the trail between access and egress points (descriptive statistics shown in Table 2). Two variables were added to account for differences in the safety and relative attractiveness of the two routes: (1) the number of intersections along both the taken route, and the shortest routes, and (2) the number of bicycle crashes reported between 1999 and 2002 on both routes during the same time period.

The first model represents each respondent with two cases: one for the calculated shortest path route and another for the chosen route. The dependent variable in this regression is the distance of the route traveled (ln). Keeping all other variables constant, the statistically significant coefficient from the dummy variable for the route suggests that the chosen path was longer than the shortest-distance path by $67 \%\left(\mathrm{e}^{0.515}\right)$. Another factor positively associated with trip distance is the number of intersections. Relative to the Greenway (the omitted category), those surveyed on the Southwest trail had a longer trip distance. Conversely, variables negatively associated with trip distance include age of the respondent and trips where respondents were surveyed on the Kenilworth trail. The number of intersections is highly associated with the trip distance and is expected; the two are in the same geographic vicinity and longer trips typically have more intersections. 
Table 2 Descriptive statistics for variables introduced in the regression analysis

\begin{tabular}{|c|c|c|c|c|c|}
\hline Variables & Mean & $\begin{array}{l}\text { Std. } \\
\text { dev. }\end{array}$ & Min & Max & $\begin{array}{l}\text { Used in } \\
\text { model }\end{array}$ \\
\hline \multicolumn{6}{|l|}{ Respondent characteristics } \\
\hline Yearly instances of trail use & 147.98 & 141.31 & 1.00 & 720.00 & $1 \& 2$ \\
\hline Respondent age & 40.09 & 13.99 & 14.00 & 79.00 & $1 \& 2$ \\
\hline Respondent is female & 0.43 & 0.50 & 0.00 & 1.00 & $1 \& 2$ \\
\hline Respondent is white & 0.97 & 0.17 & 0.00 & 1.00 & $1 \& 2$ \\
\hline Residence outside Minneapolis & 0.18 & 0.38 & 0.00 & 1.00 & $1 \& 2$ \\
\hline Surveyed on Kenilworth Trail & 0.09 & 0.29 & 0.00 & 1.00 & $1 \& 2$ \\
\hline Surveyed on Southwest LRT trail & 0.10 & 0.30 & 0.00 & 1.00 & $1 \& 2$ \\
\hline Surveyed in the afternoon/evening & 0.77 & 0.42 & 0.00 & 1.00 & $1 \& 2$ \\
\hline Surveyed on weekend & 0.33 & 0.47 & 0.00 & 1.00 & $1 \& 2$ \\
\hline \multicolumn{6}{|l|}{ Trip characteristics } \\
\hline Trip purpose is work/school & 0.55 & 0.50 & 0.00 & 1.00 & $1 \& 2$ \\
\hline Trip purpose is shopping & 0.18 & 0.39 & 0.00 & 1.00 & $1 \& 2$ \\
\hline Difference in number of crashes between routes & -19.60 & 46.25 & -109.00 & 141.00 & 2 \\
\hline $\begin{array}{l}\text { Difference in number of intersections between } \\
\text { routes }\end{array}$ & -30.89 & 76.41 & -256.00 & 264.00 & 2 \\
\hline Length of trip traveled along a trail & 3973.70 & 2344.40 & 233.71 & 12063.00 & 2 \\
\hline Is the trip taken or shortest & na & na & na & na & na \\
\hline Number of crashes along route & 56.29 & 40.93 & 1.00 & 217.00 & 1 \\
\hline Number of intersections along route & 132.65 & 87.42 & 14.00 & 558.00 & 1 \\
\hline
\end{tabular}

The dependent variable in Model 2 is the difference between the chosen route and the shortest distance route ( $\ln ($ chosen - shortest)). In this model and as shown in Table 3 , any statistically significant differences are most reliably traced back to measures used to account for differences in the relative attractiveness and safety of the two routes: the number of intersections on the taken route minus the number of intersections on the shortest route. In addition, a distance variable is introduced to account for the length of the trip being traveled along a trail.

Observing the statistically significant variables, the distance traveled along the trail has a positive effect on the difference between the chosen route and the shortest-distance route. Respondents who travel longer distances on the trail itself, all else being held constant, were more likely to travel greater distances in order to take a route that incorporates a trail. If users know they will be traveling a long distance on the trail itself, they may be more willing to travel out of their way to get there. For one additional meter traveled along the trail, the difference between chosen and taken route is expected to increase by $0.03 \%$. Assuming that the average distance traveled along a trail is approximately 4,000 $\mathrm{m}$, these results suggest that the average taken trip will be longer than the shortest by approximately $120 \%$. Meanwhile, the difference in the number of intersections between the two routes has a positive effect on the difference in the route length. One additional intersection leads to a $0.8 \%$ increase in the difference in route length. Consequently, this model suggests that bicyclists are willing to endure a route with more intersections that also incorporates a trail segment. 
Table 3 OLS regression models

\begin{tabular}{|c|c|c|c|c|}
\hline \multirow[t]{2}{*}{ Variables } & \multicolumn{2}{|l|}{ Model 1} & \multicolumn{2}{|l|}{ Model 2} \\
\hline & Coefficient & $t$-Stat. & Coefficient & $t$-Stat. \\
\hline Constant & $7.99 * * *$ & 57.93 & $5.969 * * *$ & 10.09 \\
\hline Yearly instances of trail use & 0.000 & -0.826 & 0.001 & 0.3662 \\
\hline Respondent age & $-0.003 * *$ & -2.441 & 0.002 & 0.4154 \\
\hline Respondent is female & -0.020 & -0.505 & 0.145 & 0.8611 \\
\hline Respondent is white & 0.078 & 0.687 & -0.408 & -0.8352 \\
\hline Residence outside Minneapolis & -0.033 & -0.629 & 0.285 & 1.248 \\
\hline Surveyed on Kenilworth trail & $-0.192 * * *$ & -2.978 & -0.349 & -1.279 \\
\hline Surveyed on Southwest trail & $0.191 * * *$ & 2.787 & -0.530 & -1.648 \\
\hline Surveyed in the afternoon/evening & -0.072 & -1.554 & 0.279 & 1.413 \\
\hline Surveyed on weekend & -0.049 & -0.994 & 0.339 & 1.573 \\
\hline Trip purpose is work/school & -0.031 & -0.534 & 0.242 & 0.9738 \\
\hline Trip purpose is shopping & -0.013 & -0.234 & -0.046 & -0.1879 \\
\hline Number of crashes along route & -0.001 & -0.993 & & \\
\hline Number of intersections along route & $0.006 * * *$ & 19.140 & & \\
\hline Difference in number of crashes (chosen-shortest) & & & 0.001 & 0.3609 \\
\hline Difference in number of intersections & & & $0.008 * * *$ & 4.278 \\
\hline Route traveled $(=1)$, shortest distance $(=0)$ & $0.515 * * *$ & 14.190 & & \\
\hline Length of trip traveled along a trail & & & $0.0003 * * *$ & 8.71 \\
\hline Adjusted $R^{2}$ & 0.7756 & & 0.5064 & \\
\hline$N$ & 282 & & 141 & \\
\hline Dependent variable & $\begin{array}{c}\text { Distance of } \\
\text { traveled }\end{array}$ & $\begin{array}{l}\text { oute } \\
\text { a) }\end{array}$ & $\begin{array}{l}\text { Difference } \\
\text { (chosen }\end{array}$ & $\begin{array}{l}\text { ute distance } \\
\text { ortest) (ln) }\end{array}$ \\
\hline
\end{tabular}

*Significant at the $90 \%$ level, **significant at the $95 \%$ level, ***significant at the $99 \%$ level

Several other variables, while failing to reach levels of statistical significance, reliably had a strong effect on the difference in the length between the shortest and the taken routes. We expected these variables to have a stronger affect because they have, in some manner, been shown to theoretically affect cyclist behavior in other studies. Some of the independent variables capture the time the respondent filled out the survey. The difference in distances is expected to increase by $32 \%$ if the survey was conducted in the afternoon, while keeping all other variables constant. Similarly if the respondent was surveyed during a weekend day, the difference increased by $40 \%$. Accordingly this can be mainly related to the fact that afternoon and weekend trail users typically have fewer constraints on their time and therefore more willing to travel further in order to use a trail. Many of the reported destinations were recreational events like art fairs; using the trail to get to such an event may be part of the attraction, making the trail a de facto destination. Users residing outside the City of Minneapolis are more likely to divert from the shortest route. Residing outside the City of Minneapolis leads to an increase in the difference between the chosen and shortest routes by $32 \%$. In addition, people using the Greenway experienced an increase in the difference between their actual and shortest trip by $40 \%$ relative to users of the Kenilworth Trail and $70 \%$ more than the Southwest trail 
users. Surprisingly, the difference in the number of crashes played a negligible role in affecting travel distance. ${ }^{7}$

\section{Discussion and conclusions}

The results from this detailed analysis represent a notable effort to understand the travel behavior of cyclists associated with an urban trail system. At the outset, two questions were posed: (1) how far are users willing to travel to use the trail system, and (2) what are the factors that prompt a cyclist to go out of their way to use the trail and how far is this distance?

The above analysis empirically demonstrates that a cogent decay pattern exists; more than half of the users cycled less than 2,500 $\mathrm{m}$ to reach the trail and there was a sharp decline thereafter. Furthermore, the purpose of the trips notably affected the shape of decay curves. The second part of the analysis describes how many bicyclists are in fact willing to travel substantially out of their way in order to use a high-quality off-street bicycle facility, on average a distance of about $4.21 \mathrm{~km}$ (2.6 miles), which represents a $67 \%$ increase over the shortest distance. The effect is heightened on weekends and on longer trips. Users do not seem to be deterred by intersections.

The results have several implications for planning and policy. The distance-decay functions represent integral elements of the impedance function typically used in measures of accessibility for land use-transportation modeling. Such a function is almost always theoretically derived and the same function is applied to myriad destinations and trip purposes. This application has uncovered reliable functions that could be used for detailed modeling purposes.

Second, this information can be used to guide the spacing of new trails to maximize levels of use. For planning purposes, one might assume that the additional distance traveled is divided approximately equally between the distance from origin to trail access and from trail egress to destination, about $2.1 \mathrm{~km}$ (1.3 mile) for each segment. This suggests that offroad bicycle facilities would ideally be located $3.15-4.21 \mathrm{~km}(1.5-2.6$ miles) from one another. Focusing on the drawing power of this facility alone, the results suggest this facility is so desirable that cyclists are not only willing to travel additional distance to reach them, but will also tolerate accessing them via routes with high numbers of intersections. The appeal of bicycle facilities, as measured by the distance bicyclists are willing to travel to use them, seems to be stronger for bicyclists who will be traveling a long distance on the trail and for those making trips in the afternoons and on weekends.

Several opportunities exist to build on this analysis in future research. For example, this research examined data of people cycling to and along a highly attractive trail. Depending on the nature of other trails, or even other segments of the trail that was studied, the reader would need to consider such characteristics accordingly. More importantly, the sample of users does not allow us to infer behavior about those who do not cycle or prefer to use on-street bicycle facilities. A larger-scale, geographically based sampling frame would ideally capture these preferences. With additional sources of data, the analyst could include other pertinent explanatory variables such as the number of signalized intersections or average quality of pavement. Finally, as with every self-report survey, there are inevitable

\footnotetext{
7 We tallied the number of crashes and intersections within a $200 \mathrm{~m}$ buffer of both the shortest and chosen routes. For the route chosen, the trail segment itself was not buffered and no crashes or intersections were counted along the trail segment.
} 
reporting errors, such as assuming the user accurately reported their points of origin and destination in a manner that provides usable data. Because we were limited to the survey data gathered, it was necessary to assume that respondents used the shortest path route to get from their origin to the trail access point and from the trail egress point to the destination. It would be advantageous to employ GPS units to provide more reliable data on such behavior and for some of the questions.

Overall, this work raises a number of important data, measurement, and methodological issues for future researchers and planners looking to understand how a trail system affects the travel behavior of cyclists. Alternative sampling as well as qualitative analysis would complement this research by shedding light on some of the factors, attitudes or methods we were unable to employ in this exercise. Continued research will allow planners to more accurately predict the placement and characteristics of future facilities. We look forward to others refining and adding to these methods, which should lead to sharper research results as well as better policy decisions on bicycle facility investment.

Acknowledgements This research was supported in large part by the University of Minnesota Obesity Prevention Center. The authors thank Robb Luckow of Hennepin County for collecting and sharing the data analyzed in this report and Mike Iacono and Jessica Horning for assisting with the review of relevant literature.

\section{References}

Aultman-Hall, L., Hall, F.L., Baetz, B.B.: Analysis of bicycle commuter routes using geographic information systems. Transport. Res. Record 1578, 102-110 (1997)

Dill, J., Carr, T.: Bicycle commuting and facilities in major U.S. Cities: if you build them, commuters will use them - another look. J. Transport. Res. Board 1828, 116-123 (2003)

Hunter, W.W., Huang, H.F.: User counts on bicycle lanes and multiuse trails in the United States. Transport. Res. Record 1502, 45-57 (1995)

Lindsey, G., Nguyen, L., Bao, D.: Use of Greenway Trails In Indiana. J. Urban Plan. Develop. December, 213-217 (2004)

Luoma, M., Kauko, M., Palomäki, M.: The threshold gravity model and transport geography: how transport development influences the distance-decay parameter of the gravity model. J. Transport. Geogr. 1(4), 240-247 (1993)

Merom, D., Bauman, A., Vita, P., Close, G.: An environmental intervention to promote walking and cycling - the impact of a newly constructed Rail Trail in Western Sydney. Preventive Med. 36, 235-242 (2003)

Nelson, A.C., Allen, D.: If you build them, commuters will use them: association between bicycle facilities and bicycle commuting. Transport. Res. Record 1578, 79-83 (1997)

Pikora, T., Giles-Corti, B., Bull, F., Jamrozik, K., Donovan, R.: Developing a framework for assessment of the environmental determinants of walking and cycling. Soc. Sci. Med. 56, 1693-1703 (2003)

Pucher, J., Komanoff, C., Schimek, P.: Bicycling renaissance in North America? Recent trends and alternative policies to promote bicycling. Transport. Res. Part A 33, 625-654 (1999)

Pucher, J., Renne, J.: Socioeconomics of urban travel: evidence from the 2001 NHTS. Transport. Quart. 57, 49-77 (2003)

Rietveld, P., Daniel, V.: Determinants of bicycle use: do municipal policies matter? Transport. Res.: Part A. 38, 531-550 (2004)

Shafizadeh, K., Niemeier, D.: Bicycle journey-to-work: travel behavior characteristics and spatial attributes. Transport. Res. Record 1578, 84-90

Stinson, M.A., Bhat, C.R.: Commuter bicyclist route choice- analysis using a stated preference survey. Transport. Res. Record 1828, 107-115 (2003)

Taylor, P.J.: Distance Decay Models in Spatial Interactions. Geo Abstracts Ltd., Norwich, UK (1975)

Tilahun, N., Levinson, D.M., Krizek, K.J.: Trails, lanes, or traffic: the value of different bicycle facilities using an adaptive stated preference survey. Transport. Res. Part A 41, 287-301 (2005)

Troped, P., Saunders, R., Pate, R., Reininger, B., Ureda, J., Thompson, S.: Associations between selfreported and objective physical environmental factors and use of a community rail-trail. Prevent. Med. 32, 191-200 (2001) 
Untermann, R.K.: Accommodating the Pedestrian: Adapting Towns and Neighborhoods for Walking and Bicycling. Van Nostrand Reinhold, New York (1984)

Zhao, F., Chow, L.-F., Li, M.-T., Ubaka, I., Gan, A.: Forecasting transit walk accessibility. Transport. Res. Record 1835, 34-41 (2003)

\title{
Author Biographies
}

Kevin J. Krizek is an Associate Professor of Planning and Design at the University of Colorado where he directs the Active Communities/Transportation Research Group. His research interests include land usetransportation policies and programs that influence household residential location decisions and travel behavior. He has published in the areas of transportation demand management, travel behavior, neighborhood accessibility, and sustainable development. He earned a Ph.D. in Urban Design and Planning and M.S.C.E. from the University of Washington in Seattle. His master's degree in planning is from the University of North Carolina at Chapel Hill and his undergraduate degree is from Northwestern University.

\begin{abstract}
Ahmed El-Geneidy is a Post-Doctoral research fellow at the Department of Civil Engineering, University of Minnesota and Humphrey Institute of Public Affairs. El-Geneidy's research interests include transit operations, travel behavior, land use and transportation planning, and accessibility/mobility measures in urban areas. He earned B.S. and M.S. degrees from the Department of Architectural Engineering at the University of Alexandria, Egypt, and continued his academic work at Portland State University, where he received a Graduate GIS Certificate and earned a Ph.D. in Urban Studies from Nohad A. Toulan School of Urban Studies and Planning.
\end{abstract}

Kristin Thompson was a research assistant with ACT and currently works for Metro Transit in Minneapolis, Minnesota. 